\title{
Effect of Soaking Time on the Mechanical Properties of Annealed Cold-Drawn Low Carbon Steel
}

\author{
Nurudeen Adekunle Raji, Oluleke Olugbemiga Oluwole \\ Mechanical Engineering Department, University of Ibadan, Ibadan, Nigeria. \\ Email: kunle-raji@yahoo.com, leke_oluwole@yahoo.co.uk
}

Received February $21^{\text {st }}, 2012$; revised April $15^{\text {th }}, 2012$; accepted June $11^{\text {th }}, 2012$

\begin{abstract}
The paper presents the results of investigation on the effect of soaking time on the yield strength, ductility and hardness properties of annealed cold-drawn low carbon steel. The low carbon steel cold-drawn at $40 \%$ deformation was annealed at $900 \mathrm{deg}$ Celsius for soaking times of 10, 20,30, 40, 50 and 60 minutes. Tensile, charpy and Brinnel hardness tests were conducted to determine the yield strengths, tensile strengths, impact strengths, ductility and hardness of the annealed steel with increasing soaking time. The yield strength, tensile strength, hardness and impact strength of the steel showed a continuous drop in value with increasing soaking time up to 60 minutes with a steep drop between 30 and 40 minutes. Ductility values followed the same decreasing trend up to 40 minutes soaking time after which the values started increasing again till 60 minutes soaking time. There was a linear relationship between the tensile strength and hardness of the material for different soaking times. This linear relationship was also observed for yield strength and hardness of the material.
\end{abstract}

Keywords: Cold-Drawn; Anneal; Soaking-Time; Tensile-Strength; Yield-Strength; Hardness; Toughness; Recrystallization; Grain Growth

\section{Introduction}

Wire drawing is a manufacturing process used to reduce or change the diameter of a wire or rod by pulling the wire or rod through a single or series of drawing dies. It is a plastic deformation process and mostly a cold working process. During this manufacturing process, the material experiences microstructure changes which affect its mechanical properties and consequently the product resulting from the process. The wire hardens during plastic deformation and the ductility is reduced while the tensile strength increases. The structural hardening is due to the movement of dislocation and the generation of additional dislocation within the material structure. This defect is known as strain hardening and is usually accompanied with reduced ductility of the material [1]. The distorted, dislocated structure resulting from cold working of the metal becomes unstable due to the strain hardening effect. A typical feature of such deformed structure is anisotropy of mechanical properties. An initially isotropic material responds by developing anisotropy when subjected to inelastic deformation. The inelastic induced anisotropy includes directional anisotropy in cold worked metals [2]. Unstable defect structures are retained after deformation [3].

A heat treatment procedure known as annealing is usually used to modify these defects and improve the mechanical properties of the material [4]. Annealing is a heat treatment procedure wherein a material is altered causing changes in its properties such as strength and hardness. A material is heated to an elevated temperature for a specified period of time and then slowly cooled. It is usually carried out to relieve stresses and improve ductility. The annealing process often enables the design of desired microstructure by altering the annealing parameters such as the annealing temperature and soaking time $[5,6]$. Every stage of the annealing process involves loss of some of the stored energy and a corresponding change in microstructure. The release of stored energy provides the driving force for recovery and recrystallization, but it is the nature of the microstructure that controls the development and growth of the nuclei that will become recrystallized grains and also their orientation [3].

Heat treatment for carbon steel is used to improve the mechanical properties of the steel. These properties include the yield strength, toughness, ductility, hardness and impact strength $[7,8]$. This is accomplished due to the heat treatment fundamentally altering the microstructure of the steel [9]. The various heat-treatment processes appropriate to plain-carbon steels are: annealing, normalizing, hardening, and tempering [10]. 
The annealing of cold work steel has been a subject of investigations $[11,12]$. These studies have been concerned with kinetics of recrystallization, with microstructure and texture development and with the individual and combined effects of composition, thermal history prior to cold work and heating rates during subsequent annealing. Time was considered the important parameter in the procedures of most of these studies.

Results of an investigation of annealing time and temperature on strain inhomogeneity of copper wires after drawing through dies with various die-angles and reduction of areas are presented in [13]. As an important industrial tool for the evaluation of strain, the distributions of the microhardness over the transverse cross-sections were measured. Inhomogeneity factors (I.F.), as a function of above parameters were determined. The results indicate that due to different grain growth kinetics of the coarse and fine microstructure both surface and center grains grow but with different rates in applied dies, and hence strain inhomogeneity decreases as time and temperature increase. Due to different recrystalization kinetics vs. time and temperature inhomogeneity is more sensitive to temperature rather than to time.

The effects of annealing on the mechanical properties of strain hardened coiled-rolled wire of low carbon steel were investigated in [14]. The study observed that for optimal mechanical properties of cold worked coiled wire of the low carbon steel; the material should not be strain hardened beyond the drawing of $75 \%$ draft and should be critically annealed at $650^{\circ} \mathrm{C}$ for soaking time of 15 minutes before further deformation. Secondary recrystallization in grain-oriented steels annealed at short time temperature exposures with application of dynamical heating has been investigated in [15]. Also reference [16] examined the effect of the parameters of cold deformation and recrystallization annealing on mechanical properties of a Nb-microalloyed HSLA steel. It was validated that by a sophisticated combination of size of previous cold reduction size and parameters of the following annealing it is possible to impact markedly a set of final properties of particular strips. Formability of the studied HSLA steel rises and vice versa strength properties fall with an increasing temperature of annealing. Reference [17] investigated the effects of recrystallization annealing temperature on carbide precipitation, microstructure, and mechanical properties in Fe-18Mn-0.6C-1.5Al TWIP steel. The coarsening rate of recrystallized grains was observed to increase while the Rockwell hardness greatly decreased for the material. Reference [18] modeled the cyclic annealing kinetics of thermal processing operations on cold rolled AIK steel incorporating nonisothermal rate constant. The model describes the experimental recrystallization and grain growth kinetic data carried out under cyclic conditions. The need to study the influence of annealing on the mechanical properties of low carbon steel for nail manufacture cannot be over emphasized for purpose of improving the quality of nails manufacture in Nigeria.

This paper tends to establish the effect of full annealing on the mechanical properties of cold-drawn low carbon steel as is applicable in the manufacturing industry.

\section{Experimental Procedure}

In this study, commercially available wire rod specimens drawn from as-received wire of $5.5 \mathrm{~mm}$ diameter to nominal diameters of $3.24 \mathrm{~mm}$ were selected as materials for the study. The chemical composition of the colddrawn low carbon steel is presented in Table 1. A Muffle furnace, Gallenkomp ${ }^{\circledR}$ model SVL-1009 with voltage regulation of $220 \mathrm{~V}, 50 \mathrm{~Hz}$ of temperature range $300^{\circ} \mathrm{C}$ $1000^{\circ} \mathrm{C}$ obtained in the materials test laboratory of $\mathrm{Ig}$ binedion University, Okada was used for the annealing process. The tensile tests were done at room temperature on an Instron ${ }^{\circledR} 3369$ testing machine equipped with an electro-mechanical sensor for control of tensile strain in the active zone of samples in the load range up to $50 \mathrm{kN}$. The stress-strain curves were obtained as shown in Figure 1. The hardness test was done on a Brinnel tester.

54 specimens of the cold-drawn carbon steel at $40 \%$ degree of deformation were investigated. Each of the specimens was cut to a length of $45 \mathrm{~mm}$ for purpose of the tensile tests. The specimens were heated in the Muffle furnace up to $900^{\circ} \mathrm{C}$ and soaked at the various soaking

Table 1. Chemical composition of the as-received steel wire material (wt\%).

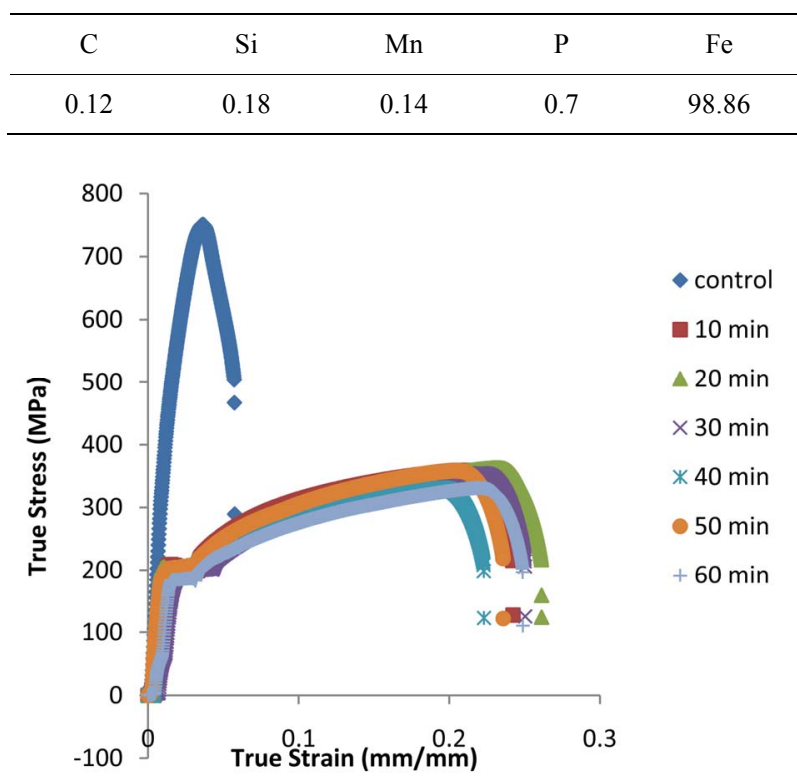

Figure 1. True stress-strain curves for $40 \%$ cold-drawn steel annealed at $900^{\circ} \mathrm{C}$ for soaking time of $10 \mathrm{~min}$ to 60 min. 
times of 10, 20, 30, 40, 50, and 60 minutes. All the specimens were cooled in the furnace down to the ambient temperature of $27^{\circ} \mathrm{C}$ and were then removed for testing.

The relative toughness at the different annealing soaking time was determined from the Charpy impact tests. For reproducibility of results, the test was done using three samples for each soaking time. The mean of the measurements were taken of the data with minima measured standard error.

In preparation for hardness measurements, scaling on the surface of each of the annealed specimens was removed in the area where the test was to be conducted. A wire brush was used to remove the surface scaling. Each specimen for the hardness test was filed to create flat surface on the nail shank. The flat surface was then polished with emery paper to obtain very smooth surface required of the test. The Brinnell test for this experiment employed a 1-mm diameter carbide ball which was pressed onto the specimen by a $1750-\mathrm{g}$ load that was maintained for 10 seconds. The diameter of the indenter impression was measured with the Brinnel reading microscope of magnification $20 \times$ and the measurement converted to the Brinell-Hardness Number on the Brinnel tester conversion table.

The samples for evaluation of the microstructures by optical microscopy (OM) were cut from the annealed wire, and taken through a grinding process on silicon carbide paper, 240, 320, 400, and 600 grit. The samples were then polished initially at $1 \mu \mathrm{m}$ and finally at $0.5 \mu \mathrm{m}$ using emery cloth and silicon carbide solution, etched with $2 \%$ nital and observed under the optical microscope (OM) with image capturing device.

\section{Results and Discussion}

Figure 1 shows a superimposed plot of the stress- strain curves for $40 \%$ cold-drawn steel soaked at different times at the annealing temperature of $900^{\circ} \mathrm{C}$.

Figure 2 shows the effect of soaking time on the yield strength of $40 \%$ cold-drawn steel subjected to an annealing treatment at $900^{\circ} \mathrm{C}$. It shows a decreasing trend of yield strength with increasing soaking time with a steep drop in value between 30 and 40 minutes soaking time.

Figure 3 shows the effect of soaking time on the tensile strength of $40 \%$ cold-drawn steel subjected to an annealing treatment at $900^{\circ} \mathrm{C}$. It shows a decreasing trend of tensile strength with increasing soaking time with a steep drop in value between 30 and 40 minutes soaking time.

Figure 4 shows the effect of soaking time on the ductility of $40 \%$ cold-drawn steel subjected to an ansnealing treatment at $900^{\circ} \mathrm{C}$. It shows a decreasing ductility with increasing soaking time up to 40 minutes soaking time after which ductility started increasing again till $60 \mathrm{mi}-$ nutes soaking time.

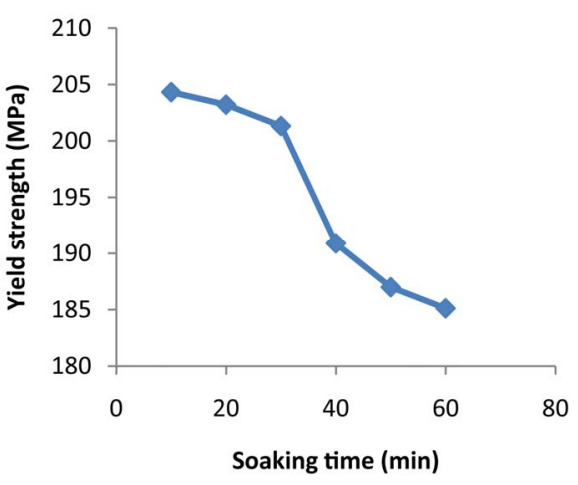

Figure 2. Influence of the soaking time of annealing on the yield strength of the $40 \%$ cold drawn low carbon steel annealed at $900^{\circ} \mathrm{C}$.

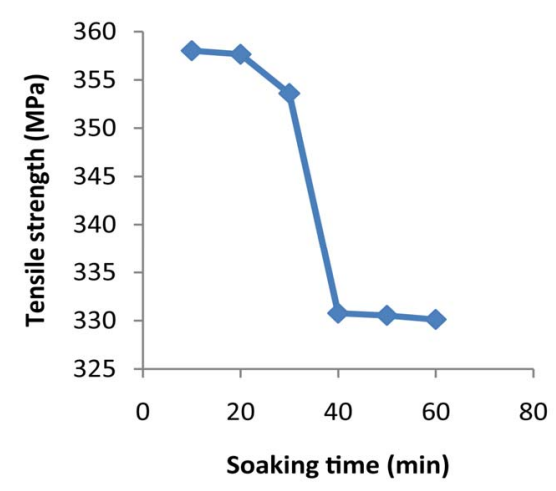

Figure 3. Influence of the soaking time of annealing on the tensile strength of the $40 \%$ cold drawn low carbon steel annealed at $900^{\circ} \mathrm{C}$.

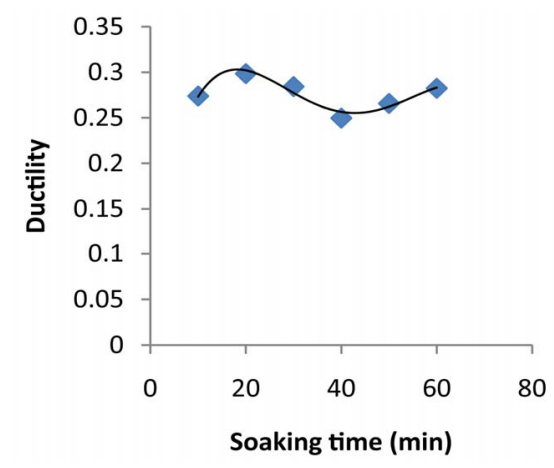

Figure 4. Influence of the soaking time of annealing on the ductility of $40 \%$ cold drawn low carbon steel annealed at $900^{\circ} \mathrm{C}$.

Figure 5 shows the effect of soaking time on the hardness property of $40 \%$ cold-drawn steel subjected to an annealing treatment at $900^{\circ} \mathrm{C}$. It shows a decreasing trend with increasing soaking time.

Figure 6 shows the effect of soaking time on the impact strength of $40 \%$ cold-drawn steel subjected to an annealing treatment at $900^{\circ} \mathrm{C}$. It shows a decreasing trend with increasing soaking time with a steep drop in value 


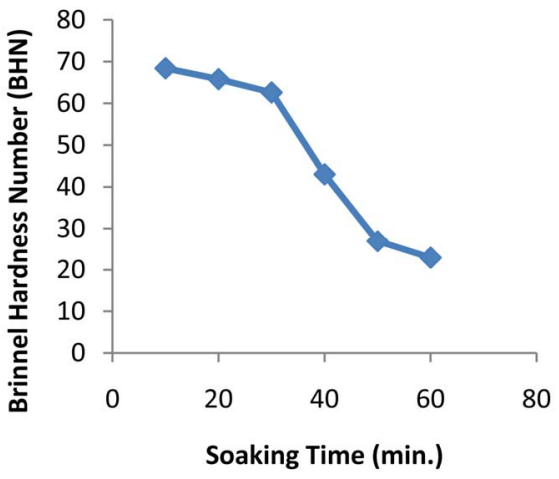

Figure 5. Hardness variation in the sample of $40 \%$ cold drawn steel annealed at $900^{\circ} \mathrm{C}$.

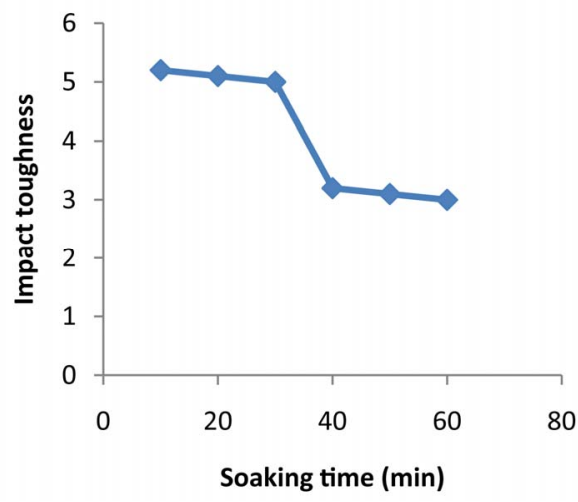

Figure 6. Impact toughness variation of $40 \%$ cold drawn steel annealed at $900^{\circ} \mathrm{C}$.

between 30 and 40 minutes soaking time.

Figure 7 shows optical microscopy of longitudinal section of the samples cold drawn at $40 \%$ and etched with $2 \%$ nital.

Figure 8 shows a plot of tensile strength with hardness for $40 \%$ cold-drawn steel subjected to an annealing treatment at $900^{\circ} \mathrm{C}$. It shows a linear relationship between them, hardness increasing with increasing tensile strength.

Figure 9 shows a plot of yield strength with hardness for $40 \%$ cold-drawn steel subjected to an annealing treatment at $900^{\circ} \mathrm{C}$. It shows a linear relationship between them, hardness increasing with increasing yield strength.

The following can be inferred from the plots. The yield strength and the tensile strength reduce with increasing soaking time. This indicates that increase in soaking time causes relief of internal stresses (residual stresses) causing a lowering in strength of the material. It was noted that soaking for $10 \mathrm{~min}$ to $30 \mathrm{~min}$, the yield strength and tensile strength reduced slowly. Probably during this treatment stage some form of stress relief (recovery) took place. The slight difference in values of the yield strength and tensile strength lends credence to the fact that recovery took place at these soaking times. It is to be noted that at the $\mathrm{AC}_{1}$, there is supposed to be full austenitizing of the

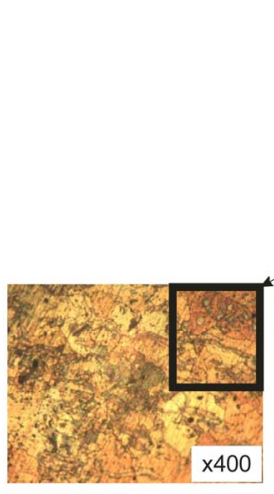

(a)

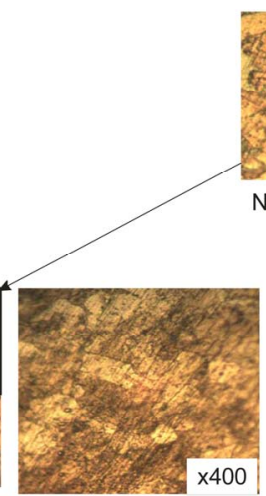

(b)

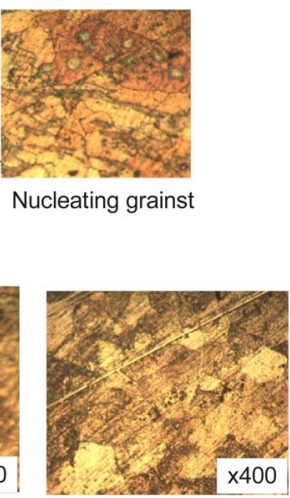

(c)
Figure 7. Optical microscopy of longitudinal section of the cold drawn samples at $40 \%$ annealed at $900^{\circ} \mathrm{C}$ for (a) $30 \mathrm{~min}$; (b) $40 \mathrm{~min}$ and (c) $60 \mathrm{~min}$.

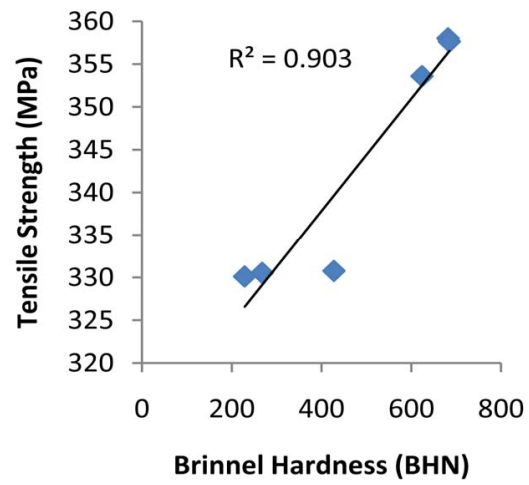

Figure 8. Directional correspondence between the BHN and Tensile strength of the $40 \%$ cold drawn steel annealed at $900^{\circ} \mathrm{C}$.

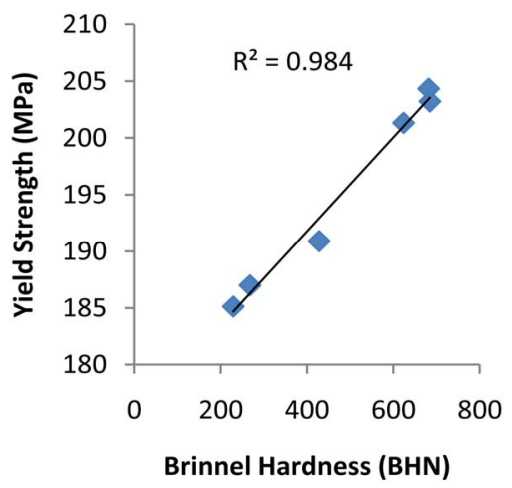

Figure 9. Directional correspondence between the BHN and Yield strength of the $40 \%$ cold drawn steel annealed at $900^{\circ} \mathrm{C}$.

grains after which the material is cooled in the furnace for full annealing to take place. All the carbon should go into solid solution at the austenite phase. As it is, total austenitization of the grains did not occur at low soaking times showing the high yield and tensile strengths at 10 , 20 and 30 minutes soaking. There was recovery occurring 
here and thus stress relief. Between 30 and 40 minutes soaking time, some form of nucleation of new austenitic grains (initial recrystallization) has started occurring but not full recrystallization. This is evident as shown by the sharp drop region of the tensile strength plot in Figure 3. The nucleating grains could also be observed on the micrograph in Figure 7(a).

Between 40 and 60 minutes soaking time shows a near stabilization of the tensile strength (Figure 3) and also increase in ductility (Figure 4) showing recrystallization occurring during that phase of soaking. This is also evident as shown in the micrograph Figures 7(b) and (c). The comparison of the stress-strain curves of the annealed steel with its control sample shows a tremendous influence of the annealing treatment on the tensile properties of the low carbon steel.

The annealed steel is characterized by slow reduction in tensile strength and hardness for the first 20 minutes of soaking time as shown in Figures $\mathbf{3}$ and $\mathbf{4}$ respectively. During this 20 minutes soaking time, the ductility of the steel rises as shown in Figure 4. The recrystallization process of the grains begins at soaking time range of 30 minutes to 40 minutes. The recrystallization taking place in the material is evident by the sudden drop of tensile strength property between the 30 minutes and 40 minutes soaking time. as shown in Figure 3.

The hardness and tensile strength of the annealed steel are related to bonding forces on the atomic level. It is therefore expected that the hardness and tensile strength of the steel are related. This relationship can be empirically defined by the relative measure of the amount of correspondence between the material hardness and its tensile properties at different soaking time. This could be expressed by the Pearson product-moment correlation coefficient [19] as:

$$
R=\frac{\sum[(B H N) *(T P)]}{\left[\sum(B H N)^{2} * \sum(T P)^{2}\right]^{\frac{1}{2}}}
$$

where $B H N$ is the hardness number at the various soaking time and $T P$ represents the tensile properties at the corresponding soaking time. Figures $\mathbf{8}$ and $\mathbf{9}$ show these correlation relationship of the properties. It could infer that the tensile properties of the material are directly proportional to the material hardness. The $R^{2}$ value which is the correlation coefficient of the relationship is shown on the Figures 8 and 9.

The results demonstrate the influence of the annealing process on the mechanical properties of the cold drawn low carbon steel. The steel when annealed at $900 \mathrm{deg}$. Celcius at different soaking time demonstrate variance in its strength. At soaking time between 10 minutes and 30 minutes, the residual stress due to cold deformation is relieved causing the strength of the steel to reduce slightly as evident in the slow reduction of its yield strength and tensile strength. It could be explained that this residual stress relief stage is a recovery stage of the steel during which new grains begins to nucleate from the highly deformed region of the steel as shown in Figure 7 (a) at soaking time between 30 minutes and 40 minutes, the new grains begins to recrystallize annihilating the deformed grains (Figure 7(b)). This process of recrystallization causes drastic reduction in the strength of the steel as shown in Figures 2 and 3. The recrystallization process ensures the reformation of the grain structure to an equiaxial grain shape desired for improved ductility of the material.

\section{Conclusion}

The effects of annealing treatment at $900^{\circ} \mathrm{C}$ on the tensile properties of cold drawn low carbon steel were investigated. It is observed that with increasing annealing soaking time, the tensile properties of the drawn steel reduces. Sharp drop in these properties is observed between the soaking time of 30 minutes and 40 minutes. It is suggested that recrystallization could possibly be taking place during this period. The hardness of the material increases at a slower rate for the first 30 minutes of soaking after which it dropped sharply between 30 minutes and 40 minutes during which the ductility reduces at a slower rate. Increase of the material ductility after 40 minutes of soaking was observed which suggested grain growth in the material. A linear correlation between the material hardness and the tensile properties is established. The yield strength, impact toughness and the ultimate tensile strength of the steel decrease with increasing annealing soaking time. The more the yield strength is lowered, the greater the plastic deformation and correspondingly the greater the possibility of reducing the residual stresses.

\section{REFERENCES}

[1] A. Phelippeau, S. Pommier, T. Tsakalakos, M. Clavel and C. Prioul, "Cold Drawn Steel Wires-Processing, Residual Stress and Ductility_Part I: Metallographic and Finite Element Analyses," Fatigue Fracture Engineering Material Structure, Vol. 29, No. 3, 2006, pp. 243-253. doi:10.1111/j.1460-2695.2005.00981.x

[2] T. Fuller and R. M. Brannon, "On the Thermodynamic Requirement of Elastic Stiffness Anisotropy in Isotropic Materials," International Journal of Engineering Science, Vol. 49, No. 4, 2011, pp. 311-321. doi:10.1016/j.ijengsci.2010.12.017

[3] F. J. Humphreys and M. Hatherly, "Recrystallization and Related Annealing Phenomena," 2nd Edition, Elsevier Ltd., Amsterdam.

[4] M. Janošec, et al., "Microstructure and Mechanical Prop- 
erties of Cold Rolled, Annealed HSLA Strip Steels," Archives of Civil and Mechanical Engineering, Vol. 7, No. 2, 2007, pp. 29-38.

[5] D. Jia, K. T. Ramesh and E. Ma, "Effect of Monocrystalline and Ultrafine Grain Sizes on Constitutive Behavior and Shear Bands in Iron," Acta Materialia, Vol. 51, No. 12, 2003, pp. 3495-3509. doi:10.1016/S1359-6454(03)00169-1

[6] C. Y. Yu, P. L. Sun, P. W. Kao and C. P. Chang, "Mechanical Properties of Submicron-Grained Aluminum," Scripta Materialia, Vol. 52, No. 5, 2005, pp. 359-363. doi:10.1016/j.scriptamat.2004.10.035

[7] J. B. Broome, "Development of a Robust Heat Treatment Process for Rockwell B-Scale Hardness Test Blocks," Master's Thesis, Massachusetts Institute of Technology, 1997.

[8] W. J. Kim, H. G. Jeong and H. T. Jeong, “Achieving High Strength and High Ductility in Magnesium Alloys Using Severe Plastic Deformation Combined with LowTemperature Aging," Scipta Materialia, Vol. 61, No. 11, 2009, pp. 1040-1043. doi:10.1016/j.scriptamat.2009.08.020

[9] P. A. O. Adegbuyi and A. Atiri, "The Effect of Annealing on the Microstructure of Mechanical Properties of a Rolled Steel Product," The Pacific Journal of Science and Technology, Vol. 10, No. 2, pp. 149-162.

[10] J. J. Hoyos, A. A. Ghilarducci, H. R. Salva, C. A. Chaves and J. M. Vélez, "Effect of Tempering on Internal Friction of Carbon Steel," Material Science and Engineering: A, Vol. 528, No. 9, 2011, pp. 3385-3389. doi:10.1016/j.msea.2011.01.051

[11] X. Song and V. Rettemayr, "Modeling Study on Recrystallization, Recovery and Their Temperature Dependence in Inhomogeously Deformed Materials," Material Science in Engineering: A, Vol. 332, No. 1-2, 2002, pp. 153-160. doi:10.1016/S0921-5093(01)01720-8

[12] J. W. Lee, J. C. Lee, Y. S. Lee, K. T. Park and W. J. Nam,
"Effect of Post-Deformation Annealing Conditions on the Behavior of Lamella Cementite and Occurrence of Delamination in Cold Drawn Steel Wires," Journal of Materials Processing Technology, Vol. 209, No. 12-13, 2009, pp. 5300-5304. doi:10.1016/j.jmatprotec.2009.03.019

[13] A. Akpari, G. H. Hasani and M. J. Jam, “An Experimental Investigation of the Effect of Annealing Treatment on Strain Inhomogeneity in the Cross-Section of Drawn Copper Wires," 2010.

[14] O. S. Olokode, B. O. Bolaji and O. O. Ize-Balogun, "Effect of Process Annealing on Mechanical Properties of Ssrain Hardened (NS 34 LC) Coiled Wire," ASSET Series, Vol. 6, No. 1, 2007, pp. 12-20.

[15] V. Stoyka, F. Kovac and B. Julius, "Study of Secondary Recrystallization in Grain-Oriented Steel Treated under Dynamical Heat Treatment Conditions," METABK, Vol. 48, No. 2, 2009, pp. 99-102.

[16] J. Schindler, M. Janošec, E. Místecky, M. Rǔžička, L. A. Čížek Dobrzdviski, S. Rusz and P. Svenanek, "Effect of Cold Rolling and Annealing on Mechanical Properties of HSLA Steel," Achives of Materials Science and Engineering, Vol. 36, No. 1, 2009, pp. 41-47.

[17] S. Kang, Y. S. Jung, J. H. Jun and Y. K. Lee, "Effect of Recrystallization Annealing Temperature on Carbide Precipitation, Microstructure and Mechanical Properties in Fe-18Mn-0.6C-1.5Al TWIP Steel," Materials Science and Engineering: A, Vol. 527, No. 3, 2010, pp. 745-751. doi:10.1016/j.msea.2009.08.048

[18] K. Krishnan, S. S. Sahay, S. Singh and D. Pal, "Modeling the Accelerated Cyclic Annealing Kinetics," Journal of Applied Physics, Vol. 100, No. 9, 2006, pp. 1-5. doi:10.1063/1.2363245

[19] R. L. Mason, R. F. Gunst and J. L. Hess, "Statistical Design and Analysis of Experiments with Applications to Engineering and Science," 2nd Edition, Wiley Interscience, 2003. 